\title{
A DESIGN INNOVATION FRAMEWORK RESEARCH IN THE CONTEXT OF SOCIAL REGENERATION
}

\author{
Duan WU', Yuhong MA ${ }^{1}$, Jie $\mathbf{X U}^{2}$ and Jiping WANG ${ }^{3}$ \\ ${ }^{1}$ College of Design \& Innovation, Tongji University Shanghai Institute of Design and \\ Innovation \\ ${ }^{2}$ College of Architecture and Urban Planning, SDAD Studio, Tongji University \\ ${ }^{3}$ School of Art Design and Media, East China University of Science and Technology
}

\begin{abstract}
This research was motivated by the lack of innovative design knowledge in the context of social regeneration. Since it is an open and diverse context, facing different methods in different disciplines, designers and the public are on the same platform. It looks for a framework to help them understand new methods and quickly get the rules of operation in various fields in response to changing social regeneration needs. This framework brings together the main methods in each area and spreads them across design stages, giving key elements that people can pick and select, and sort by their attributes. Method analysis and interviews are used to understand the effectiveness, co-design workshops are used to verify the feasibility of the proposed hypothesis.

Through case studies and analysis with multiple design methods in social regeneration and innovation, the research seeks to better understand the role of "design" and "innovation" in the interpretation projects in a modern urban context, and the role of innovation framework in the transforming complicated context to help reach out the most practical strategy. The theoretical framework is based on three concepts: open innovation, social innovation and innovative design thinking toolkit. The framework is structured to help in the social regeneration decision making process to be more replicable, scalable and operable. The outcome will also have positive impact on the related design education fields to help students understand interdisciplinary methods and use them in the complex context.
\end{abstract}

\section{Keywords: Design innovation, framework, social regeneration, methods}

\section{INTRODUCTION}

Social regeneration is an intricate field that calls for interdisciplinary knowledge to fulfil the everchanging trends and arbitrary sequence of demands. Ostensibly, involved in "reshaping" the world, for common people's thoughts, the tough work should deserve government, municipality or the minority to deal with by policy-making or one proposal file. This was not up to the task. Because, complexity is the underlying structure of social regeneration and it challenges people's traditional cognition as well as a subversion of the form of processing. They need to respond to different project scales [1], work with multidisciplinary background people, keep justice of the intricate relationships of stakeholders, seek policy and financial support, etc. It's no longer that achieving the success of regeneration by one decision-maker or one group of people within single discipline at one stroke.

Fortunately, design, which is undergoing rapid change, can provide powerful support for social regeneration. Traditional design was once seen as a craft that calls for the finely-honed intuition of the designer and it is not sufficient for the complex situation nowadays anymore [2]. Apparently, design thinking brings methods, tools, models, and theories into the process of design and makes it logical and evidence-proving [3]. These methods give designers problem-solving clues that disassembling the issues they only dimly know, perceiving the context they are barely aware of, helping them finding insights from the tremendous deposition, testing and creating the solutions that catering all stakeholders. It used to work for small-scale projects, for instance, commercial design, industrial design, etc. However, as long as the complexity and multifaceted influence take place in social regeneration, the organisation and process of design are far beyond one designer's capability. It has 
fallen upon the people, who dedicate to make big breakthrough, to draw a blueprint by using interdisciplinary knowledge, consider unmet needs from all stakeholders and gather resources into a system network. And besides, they could be designers, but non-designer people as well.

Furthermore, the other obvious change is the spotlight moving over to public participation. Comparing with the top-down "solo performance" by designers or minority of authorities, nowadays, it seems more successful to create a bottom-up public participating process. People, they are creative enough to design the world in a new collaborate way by using their experience and knowledge [4], even have the power to insurgent the city in a positive perspective [5]. The existing literature focuses on how designers inspire public participate and engage in collaborative design by using the methods in specific design fields, for instance, operable tool kits for sustainable lifestyle in community [6], mutual help group in health system [7].

In the past 40 years, China's rapid development has provided an unprecedented space for social regeneration design. The emerging new challenges in this country and its greatest capacity of application scenarios for innovation make China an ideal laboratory for practicing new design. Therefore, studying the innovation framework for social regeneration in China is significantly valuable in both practical and educational fields.

\section{RESEARCH OBJECTIVES}

This research tries to propose a framework that can be spread to the new context of interdisciplinary design and research in the context of social regeneration. It can be applied in design practice, promote integration and communication towards multiple disciplinary, and as Manzini described the form of design knowledge, it must be "explicit, discussable, transferable and accumulative" [8]. So, the feasibility of design thinking and design methods will be highlighted in establishing such an interdisciplinary collaborative process, that will help understanding the context and issues explicitly, opening up multiple possibilities to discuss, forming a discourse system for communication and information transfer, and creating accumulation form for the replication and expansion of subsequent projects.

Simultaneously, the outcome will also work as a tool kit that can be used in social regeneration, for the stakeholders who participate in the social innovation activities, helping them to formulate a design thinking clue to determine the true underlying issues and needs, concatenate a series of evidence, and propose the solution autonomously.

Precisely because creating such a format, participators are able to collaborate with a variety of interlocutors, putting themselves forwards as experts, and considering themselves as part of sticking joint of the interwoven social networks. At this point, the design is more proactive in intervening in social regeneration, and furthermore, cultivating the citizen power along with deepen participation [9].

\section{PROCESS}

\subsection{Framework Design}

The framework uses design thinking, design methods analysis and co-design in the construction of methodology. They are applicable to formulating the framework because design thinking provides an iterative flow and clarify the goals of each stage, design methods analysis is a way of screening and applying methods, and co-design engages stakeholders and the public in developing strategies to facilitate social regeneration. We design four steps: (1) defining the open design process, (2) researching on interdisciplinary methods, (3) analysing and screening the design methods by impact factors, (4) screening through handling scenarios.

\subsubsection{Define logical and open design process}

It is essential to discuss the logic and openness of the framework at the beginning of the research. A logical design process helps participants to shape up the overall concept and form the phrase goals, without getting lost in the tumultuous exploration. It draws lessons from the double diamond design model, the design thinking model of Stanford University and the IDEO design thinking process, and thus formulate an iterative design process according to the complexity of social regeneration. Moreover, it also points out the participation and co-design opportunities throughout the whole process. Obviously, along with those, all stakeholders and participators will work together and share resources through the open design process (figure 1). 


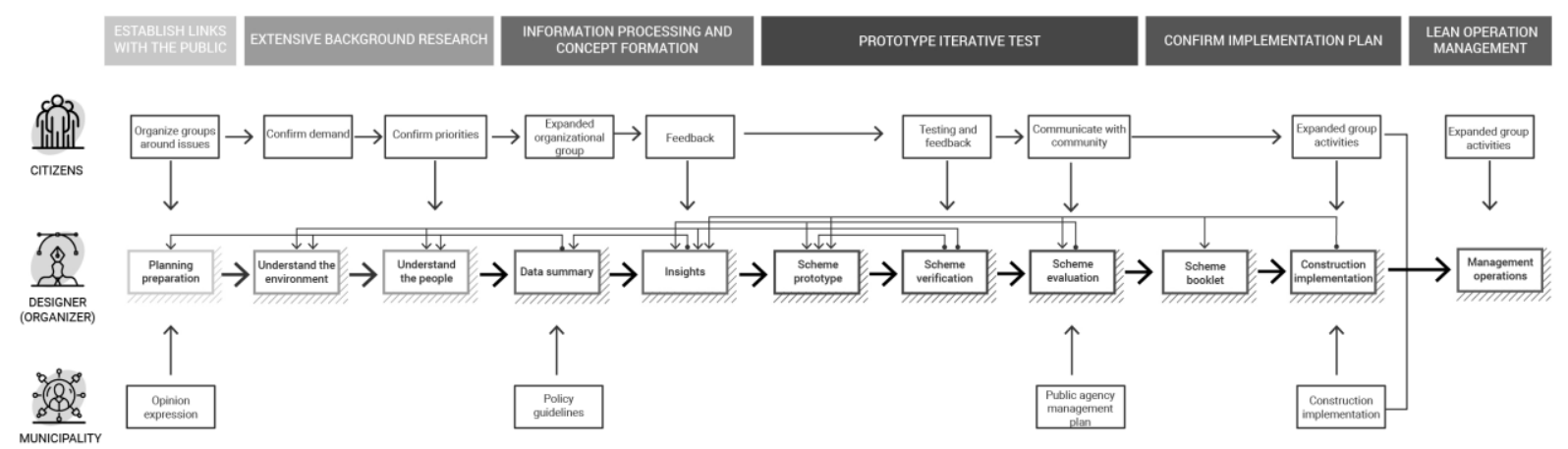

Figure 1. Open design process in social regeneration

\subsection{2 $1^{\text {st }}$ round methods screening: from interdisciplinary}

Since we cope with a progressively wide range of problems moving beyond traditional design fields, it requires room for expert opinion and theoretical considerations by using array of interdisciplinary tools and methods. We collect and organise innovative tools and methods from 14 works of literature [10-22], which were advanced in the field of service design, social innovation, business innovation, and urban planning. By analysing each of them, the selected methods are classified into six design phases that we defined above.

\subsection{3 $2^{\text {nd }}$ round methods screening: from impact factors}

Although for each design phase we gathered and analysed the available methods, it was still a dilemma that too many methods to choose, and in turn affects the operability. Moreover, as a complex social regeneration issue, the project's schedule, budget, project positioning, and the participants' own capabilities were all important factors that we cannot overlook. Through case studies and interviews with designers (including urban planners, architects and educators related with social regeneration projects), we defined six impact factors, which are accessibility (simple - complex), usability (novice expert), flexibility (linear thinking - lateral thinking), the degree of participation (creating - collecting), communication form (non-visualisation - visualisation) and the application context (business background - community environment). Accessibility refers to the degree of effort required by the user, the time may spend, and the personal knowledge input during the practice. Usability, obviously close to the personal knowledge background and capability. Flexibility shows the mode of design thinking, which is target-oriented thinking or open-horizon propose. The degree of participation determines if divergence or concentration is more in line with design expectation. Communication form describes how the design method is presented. The application context is related to the project's background. These impact factors took bipolar as format to present the degree ordering of design methods that have been chosen in each design phase. The second methods screening examples were shown in figure 2 .

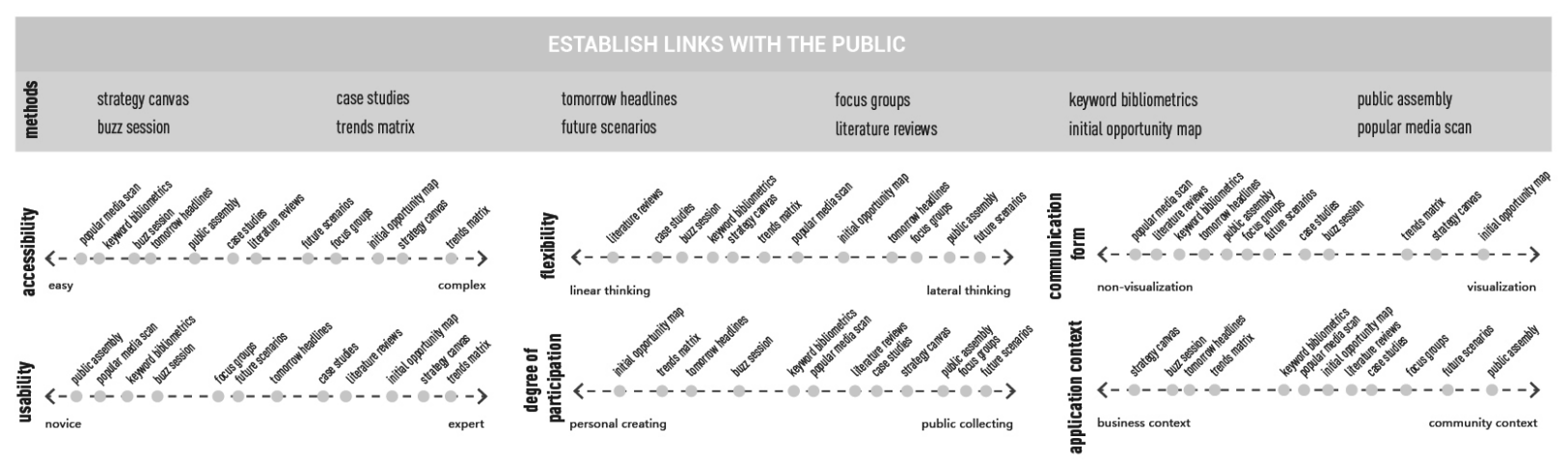

Figure 2. The second methods screening in process 1

\subsection{4 $3^{\text {rd }}$ round methods screening: from using scenarios}

Even though bipolar screening format seemingly gave the ordering of design methods in different 
impact factors at the same design stage, literally we consider these factors together. Therefore, we propose a third round of screening, which is to filter the design method by defining the use scenarios. It is a $2 \times 2$ diagram formed by a combination of the impact factors, and each quadrant represents a usage scenario. By the user evaluating the current usage scenario, the most influential combination of factors is selected to find a set of available methods. According to the characteristics of each stage, we select the two groups of factors with greater influence to combine with each other. For instance, novice organising scenario, it is interpreted by the novice users - simple quadrant, suitable for nonprofessional community to take over the development and promotion of the project. Professional indepth research scenario,

it is in professional designers - complex quadrant. (shown in Figure 3)

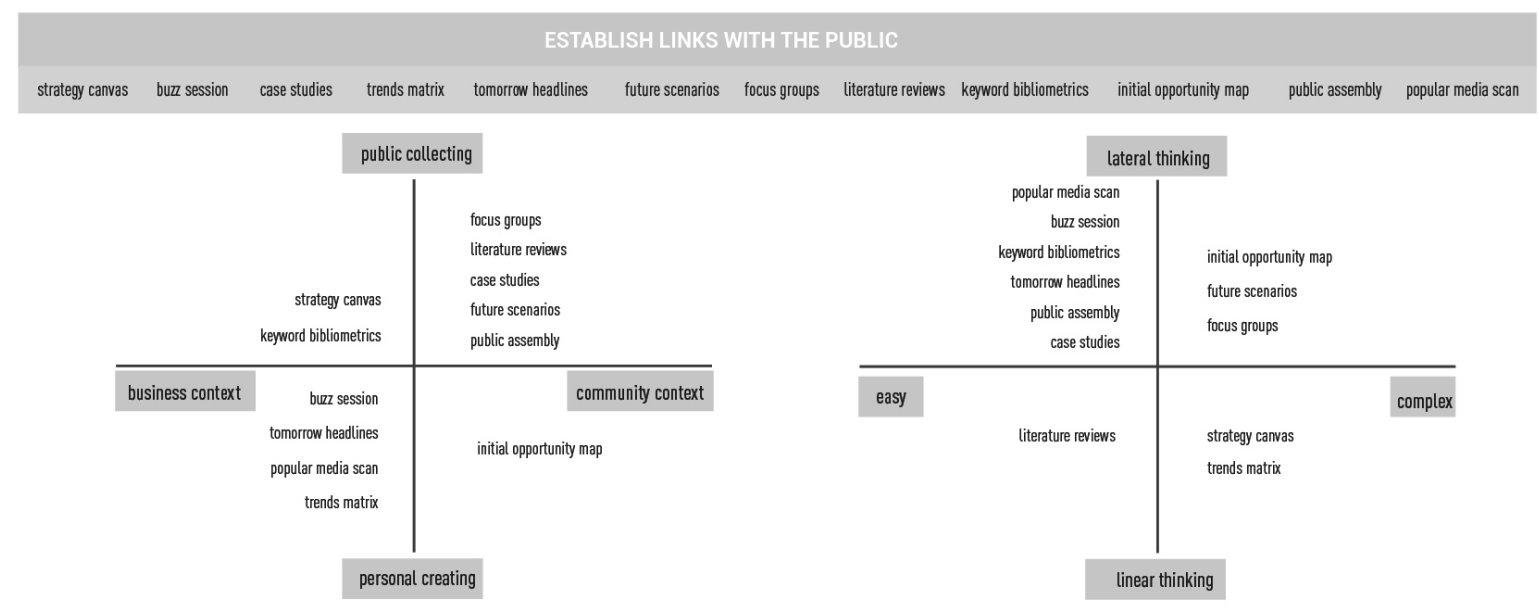

Figure 3. The third methods screening in process 1

\subsection{Framework Evaluation}

The framework is a logical process of the progressing derivation. Through subjective opinion, it has been given to what methods can be used to determine, however, what role these selected methods can play in the design process remains to be further demonstrated. Hester has proposed a technique illustration that viewed in terms of the applicability to various stages in the design process, the cost and the compatibility with other stakeholders [21]. This illustration can decompose and tease out the issues of social regeneration in four aspect: "what the methods determines, design process applicability, the cost and accommodation of other goals".

Table 1. Evaluating the methods by author

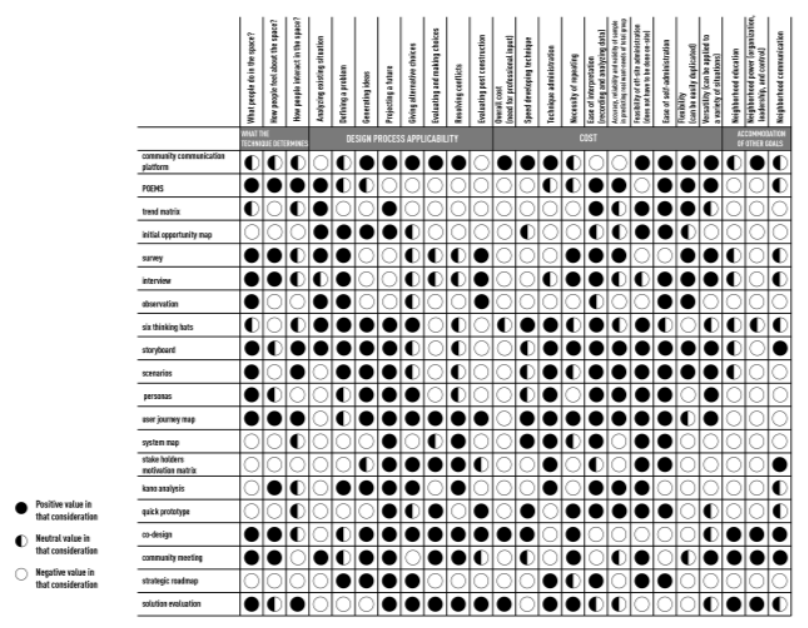

Table 2. Correcting strategies

\begin{tabular}{|c|c|c|c|c|}
\hline Expert workshop evaluation results & Author self-evaluati & ion result & Modfification principle & \\
\hline \multirow{2}{*}{$\begin{array}{l}\text { Alll } 4 \text { groups judged } \\
\text { in negative value } 4 \times 0\end{array}$} & Positive Value & - & 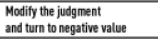 & 0 \\
\hline & Neutral Value & D & $\begin{array}{l}\text { Depend on consideration to } \\
\text { modify to negative value or not }\end{array}$ & 0 \\
\hline \multirow{2}{*}{$\begin{array}{l}4 \text { or } 3 \text { groups judeged } \\
\text { in positive value }\end{array}$} & Negative Value & 0 & $\begin{array}{l}\text { Modifir the judgnnent } \\
\text { and turn to positive value }\end{array}$ & $\bullet$ \\
\hline & Neutral Value & D & $\begin{array}{l}\text { Depend on consideration to } \\
\text { modily to negative value or not }\end{array}$ & 0 \\
\hline \multirow{2}{*}{$\begin{array}{l}2 \text { groups judeged } \\
\text { in positive value }\end{array}$} & Positive Value & - & $\begin{array}{l}\text { Depend on consideration to } \\
\text { modify to neutral value or not }\end{array}$ & D \\
\hline & Negative Value & 0 & $\begin{array}{l}\text { Depend on consideration to } \\
\text { modily to neutral value or not }\end{array}$ & D \\
\hline \multirow{2}{*}{$\begin{array}{l}1 \text { group judeged } \\
\text { in positive value }\end{array}$} & Positive Value & - & $\begin{array}{l}\text { Depend on consideration to } \\
\text { modily to neutral value or not }\end{array}$ & D \\
\hline & Negative Value & 0 & $\begin{array}{l}\text { Depend on consideration to } \\
\text { modify to neutral value or not }\end{array}$ & D \\
\hline
\end{tabular}

It the author's sell-assessment tis the same as the expert workshop's jucgement, it is retained.

As an early step of research, we exampled a fundamental assumption which was the designer as expert, deeply research the environment and user-needs, effectively organise the public in solving social regeneration problems. By using the framework of methods screening, we chose 20 methods according to the assumption, and evaluated the effectiveness and operability of the methods selected through the framework. Table 1 shown the evaluation framework. 


\subsection{Co-design Workshop}

The co-design workshop addressed with deviation that may arising in the subjective judgment of framework. We organised expert designers and researchers who dedicated in social innovation design and methods research, to carry out expert co-design workshop with two main purpose. One was to verify the feasibility of the design method selected by the authors in the design process of social regeneration, and the other was to judge validity of the selected design method through Hester's methods illustration theory. To begin with, we gave them specific regeneration task and methods with introduction and called for addressing the issues by using the tools. As they were engaged in the process of solving problems, they verified the logical accuracy of the framework and additionally were familiar with the methods that to be judged. This made it possible for them to have a hands-on experience and comprehension when they verify Hester's judgment theory in the second step, thus improving the accuracy of the assessment. Through nearly two and a half hours' teamwork by expert researchers and designers, based on their respective understandings, subsequently, four sets of design processes and corresponding design method rankings were summarised, and the role of the design method in it was judged.

\section{FINDINGS}

For the validation of the framework, the management of the design process and the selection of the design methods were basically in line with expectations. There were three groups of design processes that improved mutual and iterative verification, which mostly took place in the stages of concept Formation and prototype test. Simultaneously, the rest group categorised the methods and iterated them mutually. This part verified the feasibility of the framework to implement social regeneration.

However, there were certain deviation between the workshop results and the author's previous judgment. This leads us to speculate about what went wrong: the complexity of the design methods indicates the diversity of judgments, the different comprehensions in the role of design methods and its multiple possibilities, the uncertain definition of impact factors, the subdivision leads to similar semantics, and the degree definition is hard to quantify. Therefore, we adopted the following strategies to correct the existing evaluation method of the design method (Table 2).

a. Correct the judgment of complete opposite

Since the participants in the workshop only mark the "active role" approach, all unselected methods and all (or three) selected methods can fully account for the judgment of the method validity subdivision. Therefore, we corrected the completely opposite judgments in the existing evaluation forms for these two types of results.

b. Uncertain validity and review

If only one or two sets of data tag "play positively", they will be judged again based on the specific segmentation semantics and combined with the evaluation results of the workshop. The revised rules are shown in table 2 and the revised methods evaluation is presented in Table 3.

Table 3. Revised design methods evaluation

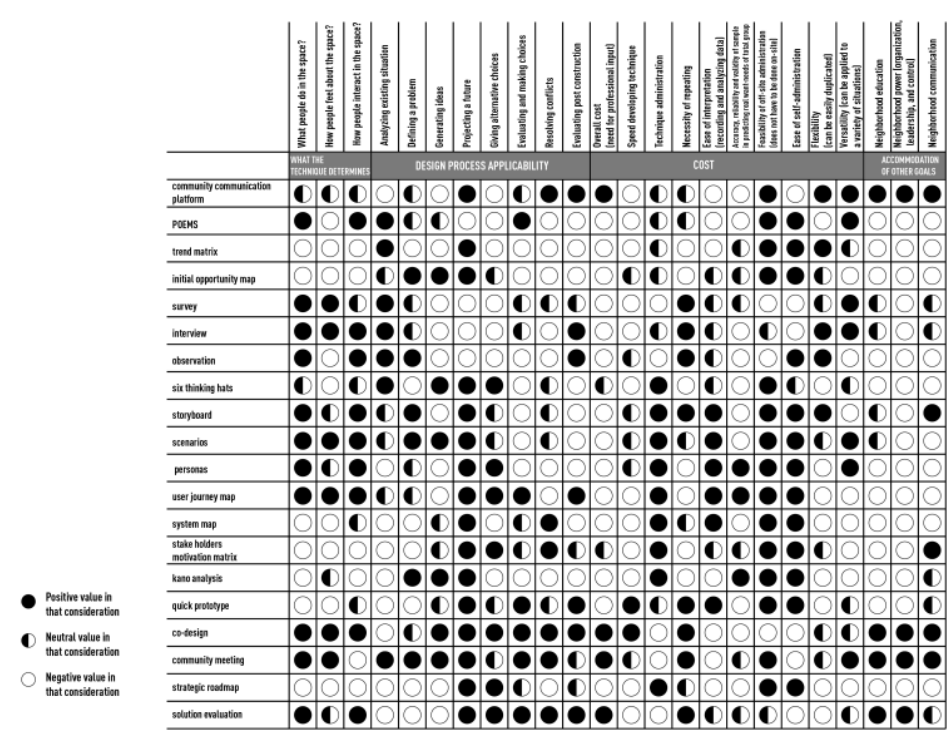




\section{CONCLUSIONS}

We proposed a framework follows the process of design thinking to foster social regeneration, meanwhile, it is also a method selection guide that explicit, discussable, transferable and accumulative. Six sets of impact factors in complex social relationship updates are defined and the widely selected design methods are ranked by them. Additionally, these factors form a selection guide for using scenarios. For validation, the methods selected through the framework were judged by Hester's evaluation theory. The expert co-design workshop validated the feasibility of the framework and provided testimony for the revision of methods evaluation. The framework and toolkit also act as a visualised tool to help understand interdisciplinary design methods during the design education process in College of Design and Innovation, Tongji University. This paper is a novel approach to social regeneration at a theoretical level as a very early step, and the investigation will continue with rooting in enhancing operability.

\section{REFERENCES}

[1] Friedman K. New Challenges for design. She Ji: The Journal of Design, Economics, and Innovation, 2016, 2(4), 271-274.

[2] Norman D.A. When you come to a fork in the road, take it: The future of design. She Ji: The Journal of Design, Economics, and Innovation, 2016, 2(4), 343-348.

[3] Cross N. Design thinking: Understanding how designers think and work, 2011(Berg).

[4] Manzini E. Design, when everybody designs: An introduction to design for social innovation, 2015 (MIT press).

[5] Hou J. Insurgent public space: guerrilla urbanism and the remaking of contemporary cities, 2010(Routledge).

[6] Jégou F. and Manzini E. Collaborative services. Social innovation and design for sustainability, 2008(Polidesign).

[7] Cottam H. and Leadbeater C. RED paper 01: Health: Co-creating services. 2004(London: Design Council).

[8] Manzini E. New design knowledge. Design studies, 2009, 30(1), 4-12.

[9] Arnstein S.R. A ladder of citizen participation. Journal of the American Planning Association, 1969, 35(4), 216-224.

[10] Kim W.C. and Mauborgne R. Blue ocean strategy, 2005(Harvard Business Press).

[11] IDEO. Human-Centred Design Toolkit: An Open-Source Toolkit to Inspire New Solutions in the Developing World, 2011(IDEO).

[12] Lockton D. Design with intent: 101 patterns for influencing behaviour through design, 2010 (Equifine).

[13] Hanington B. and Martin B. Universal methods of design: 100 ways to research complex problems, develop innovative ideas, and design effective solutions, 2012(Rockport Publishers).

[14] Kumar V. 101 design methods: A structured approach for driving innovation in your organisation, 2012(John Wiley \& Sons).

[15] Osterwalder A. and Pigneur Y. Business model generation: a handbook for visionaries, game changers, and challengers, 2010(John Wiley \& Sons).

[16] Stickdorn M., Schneider J., Andrews K. et al. This is service design thinking: Basics, tools, cases, 2011(Hoboken, NJ: Wiley).

[17] Ogilvie T. and Liedtka J. Designing for growth: A design thinking toolkit for managers, 2011(Columbia University Press).

[18] Service Design Tools. Available: http://www.servicedesigntools.org/ [Accessed on 2019, 09 March], (2009).

[19] Lewis J., Walker P. and Unsworth C. Participation Works! 21 techniques of community participation for the 21 st century,1998(New Economics Foundation, London).

[20] Urban Design Group. Involving Local communities in urban design, promoting good practice. Urban Design Quarterly, 1998, 67(06), 15-38.

[21] Hester R.T. Neighbourhood space, 1975(Dowden Hutchinson and Ross).

[22] Wates N. and Knevitt C. Community Architecture: How People Are Creating Their Own Environment, 2013(Routledge). 